\title{
A STUDY OF THE MANAGEMENT OF OPEN FRACTURES OF TIBIA BY UNREAMED INTERLOCKING NAIL
}

\section{K. Harsha Kumar ${ }^{1}$}

\section{HOW TO CITE THIS ARTICLE:}

K. Harsha Kumar "A Study of the Management of Open Fractures of Tibia by Unreamed Interlocking Nail". Journal of Evolution of Medical and Dental Sciences 2015; Vol. 4, Issue 71, September 03; Page: 12428-12446, DOI: $10.14260 /$ jemds/2015/1791

ABSTRACT: AIMS AND OBJECTIVES: 1 . To evaluate the results of closed interlocking intramedullary nailing without reaming in the treatment of open fractures of the tibial shaft. (Gustillo type 1, type 2, type 3a, type 3b). 2. To study the difficulties (Complications) encountered during the operative study. 3. To mobilize the patient early. 4. To compare the efficacy of interlocking intramedullary nailing without reaming in treating open fractures of tibia with other standard similar studies in terms of: a. Time required for the union of fracture. b. Range of motion of ankle and knee joint. c. Rate of malunion and mal rotation. d. Pain at the knee joint. e. Rate of infection. f. Failure of the implant.

INTRODUCTION: Tibial diaphyseal fractures are the most common type of long-bone fracture encountered by most orthopaedic surgeons. In an average population, there are about 26 tibial diaphyseal fractures per 100,000 of the population per year. Males are more commonly affected than females, as the male incidence is about 41 per 100,000 per year and the female incidence is about 12 per 100,000 per year. The average age of a tibial fracture population is about 37 years; males have an average age of about 31 years and females 54 years. This indicates a bimodal distribution with a preponderance of young males. ${ }^{1}$

\section{There are Five Principle causes of Tibial Diaphyseal Fractures:}

1. Falls.

2. Sports injuries.

3. Direct blows or assaults.

4. Motor vehicle accidents.

5. Gunshot injuries.

The management of tibial diaphyseal fractures has always held a particular interest for orthopaedic surgeons. Not only are these fractures relatively common, but they are often difficult to treat. The subcutaneous location of the anteromedial surface of the tibia means that severe bone and soft tissue injury is not infrequent, and there is a high incidence of open fractures compared with other long bones. Furthermore the blood supply of tibia is more precarious that of bones enclosed by heavy muscles. ${ }^{2}$

"Every fracture is an individual problem and the decision to treat it by internal fixation or indeed conservatively should be based on a realistic assessment of the advantages and the hazards of each method in the circumstances of that particular case. This calls for a high degree of clinical judgement which is harder to acquire or to impart than technical virtuosity in the operating theatre". ${ }^{2}$ The primary objective in the management of open fractures is union with prevention or eradication of wound sepsis- Gustillo et. al.

We still have long way to go before the best method of treating a fracture of the shaft of tibia can stated with finality-Sir John charnley, $1961 .^{3}$ 


\section{ORIGINAL ARTICLE}

Management of the fractured tibia requires the widest experience, greatest wisdom and the best of clinical judgment to choose the most appropriate treatment for a particular pattern of injuryWatson and Jones. ${ }^{4}$

Until recently, surgeons had to rely on non-operative management, and the incidences of nonunion, malunion, joint stiffness and infection were high and often results in employment loss or other social and economic problems. These complications also place a considerable strain on the health services of all countries.

\section{According to Nicoll, the important Factors in Prognosis are:}

1) Amount of initial displacement.

2) Degree of communition.

3) Whether infection has developed.

4) Severity of soft tissue injury excluding infection.

Among the various modalities of treatment such as conservative gentle manipulation and use of short leg or long leg cast, open reducation and internal fixation with plates and screws, intra medullary fixation and external fixation techniques, surgeon should be capable of using all these techniques and must weigh advantages and disadvantages of each one and adapt the best possible treatment. The best treatment should be determined by a thoughtful analysis of morphology of the fracture, the amount of energy imparted to the extremity, the mechanical characteristics of the bone, and the age and general conditions of the patient and most importantly the status of the soft tissues (The skin, muscle and associated neurologic and vascular structures of the leg).

\section{Three goals must be met for the successful treatment of open fractures of tibia.}

1. Prevention of infection.

2. Achievement of bony union.

3. Restoration of function.

These goals are interdependent and usually are achieved in the chronologic order given. For example failure to prevent infection promotes delayed union or non-union and delays functional recovery of the limb.

Immobilization in a plaster cast has been used most commonly in the past but it does not always maintain the length of the tibia and it leaves the wound relatively inaccessible. ${ }^{6}$

Open reduction and internal fixation with plates and screws has yielded unacceptably high rates of infection. ${ }^{7,8,9}$ This method may be selected with more severe or local injuries, associated displaced intra-articular fractures of knee and ankle.

External fixation, considered the treatment of choice by many truamatologists, has the disadvantages of the bulky frames and frequent pin track infections, nonunions, and malunions.7,10

Charley in his text closed treatment of common fractures said that he believed the eventual solution to the tibial fractures would be an unreamed intramedullary nail.11

The intra medullary nailing locked or unlocked has become an attractive option since image intensifier has made closed intramedullary nailing possible. Nail is a load sharing device and is stiff to both axial and torsional forces. Closed nailing involves least disturbance of soft tissue and fracture Hematoma.The natural process of bone healing is good as compared to other forms of internal fixation. 
The locking of intramedullary nails to the major proximal and distal fragments decreases the prevalence of malunion of communited fractures. Until recently, however all interlocking intramedullary nailing involved reaming, which destroys the blood supply. ${ }^{12}$ The rate of infection after treatment of open tibial fractures with intramedullary nailing with reaming has been relatively high, causing most investigators to discourage the use of this technique for grade II and III open tibial fractures.

This led us to design a trial, to study the results of closed interlocking intramedullary nailing without reaming in the treatment of open fractures of the tibial shaft.

\section{AIMS AND OBJECTIVES:}

1. To evaluate the results of closed interlocking intramedullary nailing without reaming in the treatment of open fractures of the tibial shaft. (Gustillo type I, type II, type IIIA and type IIIB).

2. To study the difficulties (Complications) encountered during the operative study.

3. To mobilize the patient early.

4. To compare the efficacy of interlocking intramedullary nailing without reaming in treating open fractures of tibia with other standard similar studies in terms of:
a. Time required for the union of fracture.
b. Range of motion of ankle and knee joint.
c. Rate of malunion and mal rotation.
d. Pain at the knee joint.
e. Rate of infection.
f. Failure of the implant.

MATERIALS AND METHODS: The present study was undertaken at the department of orthopedics, Narayana Medical College after obtaining ethical clearance. This study involved both male and female patients with open fractures of tibia, who presented to Narayana General Hospital. 24 patients who had open fractures of tibial shaft were treated with wound debridement and interlocking intramedullary nailing without reaming during the period from July 2012 to May 2014. All the cases were fresh fractures and were traumatic in nature.

Most of the patients were brought to the casualty. Remaining cases were admitted through the outpatient department.

The criteria for selection of the cases.

\section{Inclusion Criteria:}

1. Age more than 18 years.

2. Shaft fractures within $7 \mathrm{cms}$ distal to the tibial tuberosity to $7 \mathrm{~cm}$ proximal to the ankle joint in tibia in which the medullary canal was large enough to accept a minimum $8 \mathrm{~mm}$ nail.

3. Fresh fractures.

4. Open fractures type I, II, IIIA and IIIB according to Gustilo Anderson classification.

\section{Exclusion Criteria:}

1. Ageless 18 years.

2. Associated intra articular fractures of proximal/distal tibia.

3. Closed fractures and Gustilo type IIIC fractures.

4. Patients with associated head injury, chest and abdominal trauma necessitating delay in primary and immediate fixation. 
Twenty four patients who had twenty four fractures were available for evaluation. The duration of follow-up ranged from 6 to 10 months (average 8 months). There were twenty men and four women, ranging in age from 18 to 66 years old, with an average age of thirty two years. Fourteen right and ten left tibia was fractured.

Most of the fractures were caused by high energy trauma. Twelve of the fractures were caused by pedestrian-automobile accidents, seven by motor cycle accidents, there by motor vehicle accidents and two by falls.

The soft tissue injuries are classified according to the system of Gustilo et. al; ten wounds were type I, twelve wounds were type II, and two were type IIIA.

Location of the fracture, the tibia was divided into five zones of equal length; there were no proximal third fractures, one fracture was in proximal middle third; eight fractures were in middle third, eleven fractures were in middle distal third, four fractures were in distal third and no segmental fractures. The tibial fracture patterns were transverse in four, oblique in four, wedge in five, spiral in one, and communited in ten and no segmental fractures.

On admission a thorough clinical examination was performed including detailed history relating to age, sex, occupation, mode of injury, past and associated medical illness. The general condition of the patient was assessed with regards to hypovolemia, associated orthopaedic or other systemic injuries and resuscitative measures were taken accordingly. All patients received analgesics in the form I.M injections, tetglob 500 I.U intramuscularly and antibiotics I.V. patients were taken to the emergency operating room for irrigation and debridement of the open fracture. Swabs were taken from the wound and were sent for culture and sensitivity, thorough saline wash was given and primary closure was done for the wounds presenting within 6 hours of trauma and which were clean. A sterile dressing was given for wounds and limb was immobilized in the form of above knee plaster of paris slab. Limb elevation over a pillow was given for all the patients.

All patients were evaluated clinically and radiographically to assess for any other injuries. Radiographs were taken in two planes, AP and Lateral views. I.V antibiotics, cephalosporins and aminoglycosides were started for all the patients, patients were operated as early as possible, once the general condition of the patients was stable and fit for surgery.

Preoperatively the length of the nail was calculated from measurement taken from tibial tubercle to tip of the medical malleous clinically and medullary canal was measured at the isthmus from the radiographs.

\section{Pre-operative Preparation of the Patients:}

- Patients were kept nil orally for 8 to 10 hours before surgery.

- Adequate amount of compatible blood if needed was arranged.

- Preparation of whole extremity/private parts and back was done.

- Written informed consent was taken.

- Soap water enema H. S.

- Tranquilizers H. S.

- I.V antibiotics $30 \mathrm{~min}$. before the procedure and shifted to OT.

Surgical Technique: We operated the patients under spinal/general anesthesia patient is placed in supine over a radiolucent operating table. The injured leg is positioned freely, with knee flexed $90^{\circ}$ over the side of operating table to allow traction by gravity. The uninjured leg is placed in extension. Esmarch rubber tourniquet was used in all patients. 
The affected limb is thoroughly scrubbed from mid-thigh to foot with savlon and povidine iodine scrub. Then limb is painted with povidine iodine solution from mid-thigh to foot. Reset of the body other limb and foot is properly draped with sterile drapes.

Determination of Nail Length: Hold the radiographic ruler parallel to tibial shaft in such a way that the proximal end comes to lie at proximal end comes to lie at the level of the insertion point. Mark the skin at the appropriate point. Position the image intensifier over the distal tibia. Align the measuring ruler at the skin marking with correct reduction.

In another way to measure the length of nail is, if using the Hollow and tubular nails the exposed length of the guide rod and subtract this from its total length of $950 \mathrm{~mm}$.

Determination of Nail Diameter: The marking on the radiographic ruler may be used to determine the diameter of the medullary canal with square marking over the isthmus, to determine whether to use $8 \mathrm{~mm}$ or $9 \mathrm{~mm}$ nail.

Surgical Procedure: A vertical skin incision was made extending from centre of the inferior pole of patella to the tibial tuberosity about $5 \mathrm{~cm}$ long. Split the patellar tendon vertically in its middle and retract it to reach the proximal part of tibial tuberosity. The point of insertion is determined, which should be slightly distal to the tibial plateau, slightly medial and exactly in line with the medullary canal. If the insertion point is too distal, there is a danger of fracturing the distal cortex of the main proximal fragment, and too proximal, bears the risk of opening the knee joint. After selecting the point of insertion curved bone awl was used to breach the proximal tibial cortex in a curved manner, so that from perpendicular position its handle comes to be parallel to the shaft.
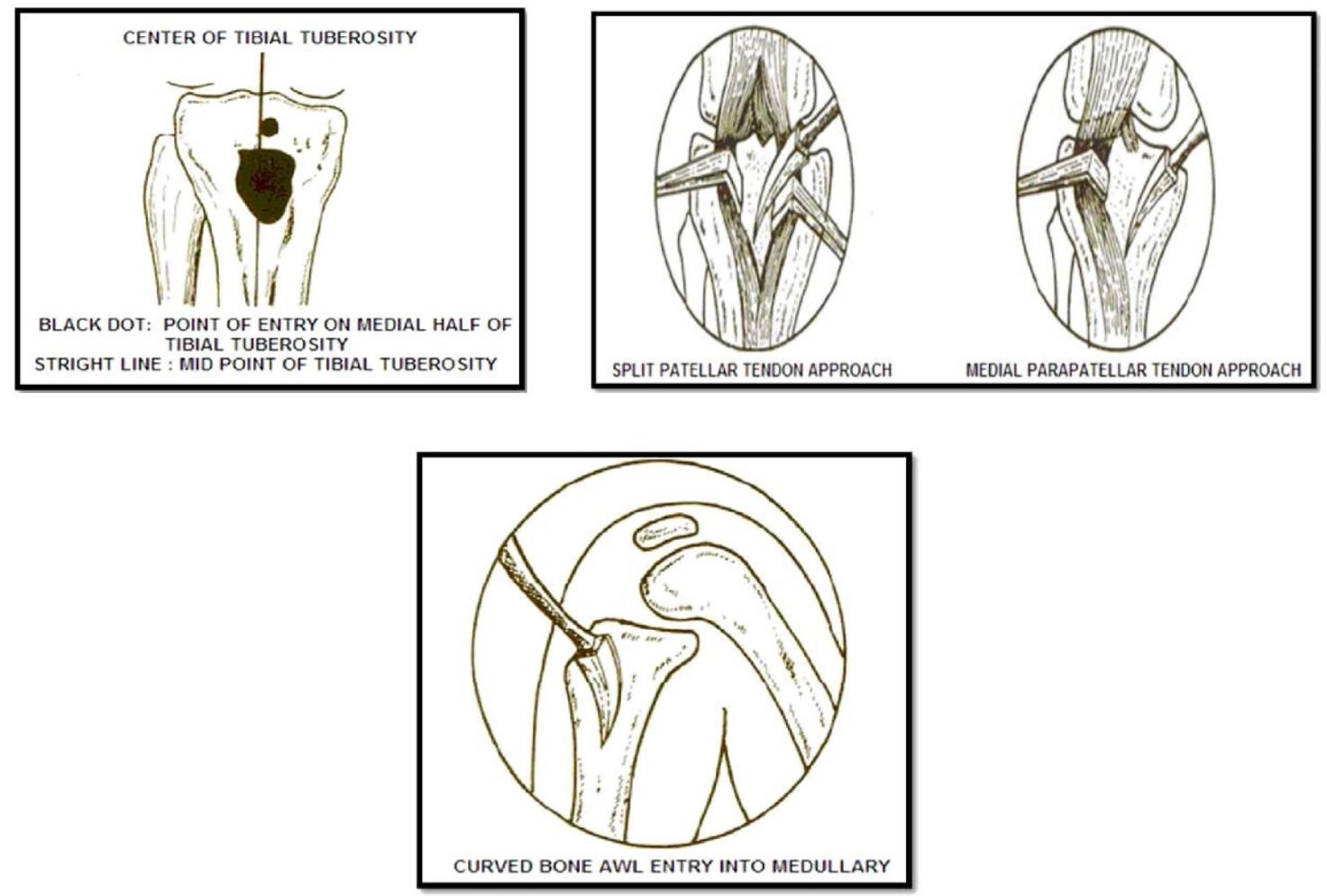


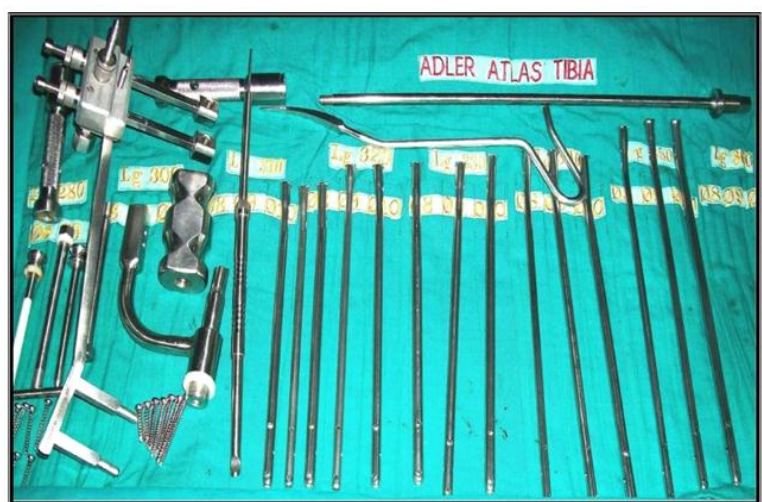

Unreamed Tibial Nail - AO (Adler)

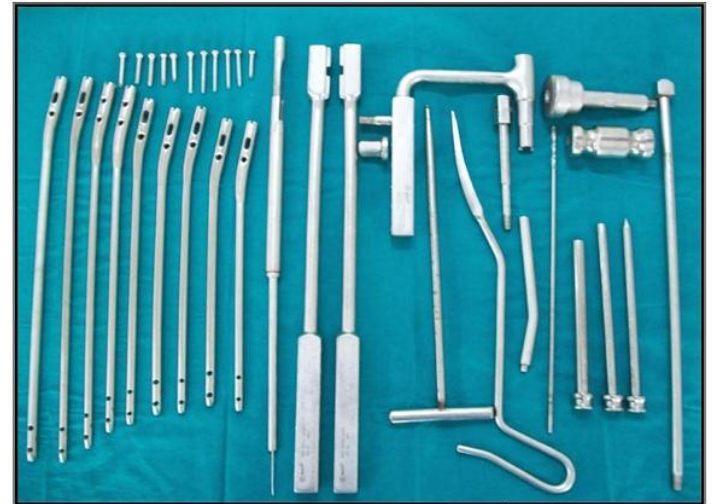

Hallow and Tubular Nails - Indian (SSPL)

Solid Unreamed Tibial Nail (A0): Selected nail of appropriate diameter and length was assembled into the jig and passed into the medullary canal of proximal fragment and reduction of the fracture fragments was done maintaining longitudinal traction in the line of tibial. Nail was pushed into distal fragment after reducing the fracture and confirming under image intensifier. Insertion was aided by gentle blows with the slotted hammer until distal end of nail was slightly counter sunk in the bone and confirmed under image intensifier.

Routinely we prefer proximal locking carried out first, but if gap present at the fracture site we carried out distal locking first, it enables the use of the rebound technique to prevent diastasis. The insertion handle was used to locate the holes for proximal locking screws.

Next step is distal locking; several distal locking options are available to the surgeon. Using free hand technique with an image intensifier provides a convenient method for targeting the distal locking holes. In our study all cases we locked mediolateral hole in free hand technique under image intensifier. The entire leg and the fracture site visualized finally in both views for the proper placement of nail.

Hollow and Tubular Interlocking Nails (Indian): After widening the medullary canal proximally $1 / 3^{\text {rd }}$, the guide wire $3 \mathrm{~mm}$ diameter $\mathrm{x} 950 \mathrm{~mm}$ length was passed into the medullary canal of proximal fragment and reduction of the fracture fragments was done by maintaining longitudinal traction in the line of tibia.

After reduction, the tip of guide wire was adjusted to pass in the distal fragment up to $0.5-1 \mathrm{~cm}$ above the ankle joint under image intensifier and its containment within the tibia was confirmed by AP and lateral views. Now the selected nails was assembled and was pushed into the medullary canal over the guide wire into distal fragment. After confirming the fracture reduction, distal part and proximal part if nail, guide wire was removed, the nails was locked distally and proximally with the help of distal and proximal locking jig. This method can be advocated without image intensifier. The other method we used is of free hand technique under image intensifier.

Later the incision site was washed thoroughly. Esmarch rubber tourniquet was removed. Incision was closed in layers after securing haemostasis. Wound dressing was done. Capillary filling and peripheral arterial pulsations were checked.

In our study we used guide wire for hollow and tubular nails (Indian nails). Whereas in case of solid AO unreamed tibial nail, we passed the nail directly into the medullary canal. 


\section{Postoperative Instructions:}

- NBM for 4-6 hours postoperatively.

- I.V Fluids/Blood transfusions (if necessary).

- I.V Antibiotics and Antacids and I.M Analgesics.

- Limb elevation over pillows and watch for active bleeding.

- Active toe movements.

- $\quad \mathrm{TPR} / \mathrm{BP}$ and Input/output chart hourly.

Postoperative Care: Intravenous antibiotics were given for 5 days post-operatively. Culture from the wound was sent if necessary. Switch over to oral antibiotics was done on $6^{\text {th }}$ postoperative day.

Active knee, ankle and toe mobilization started after recovery from anaesthesia. Primary dressing was done on second postoperative day. Check x-ray of the operated tibia (Full length) including knee and ankle joints in both AP and lateral views were obtained. Patient was allowed non weight bearing crutch walking on second postoperative day. Skin sutures, were removed on $10^{\text {th }}$ postoperative day.

Partial weight bearing, crutch walking/ walker commenced after 10 days, depending upon the type of fracture and rigidity of fixation. Further follow up is done at 6 weekly intervals and each patient was individually assessed clinically and radiographically and documented.

SECODARY PROCEDURES: If fracture was not showing any sign of consolidation by 8-12 weeks dynamization was done by removing locking screw from the longer segmen Efforts were made to obtain definitive coverage of the wound within 7 days. In two patients split thickness skin grafting was done. In one patient the wound was covered with Fascio-cutaeneous flap.

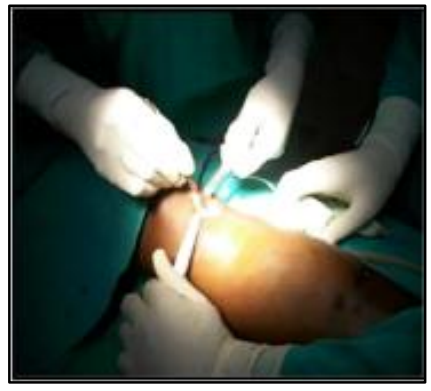

INCISION

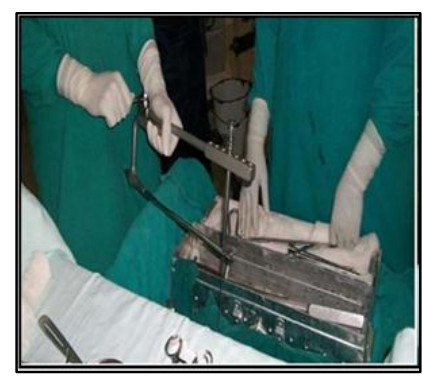

ASSEMBLING NAIL INTO JIG

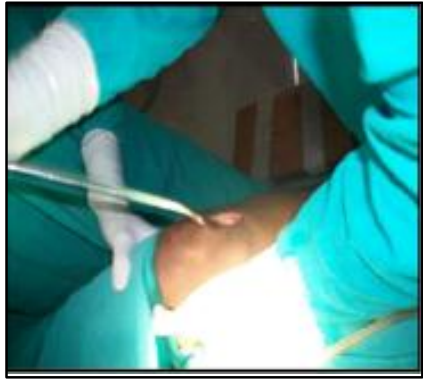

ENTRY OF BONE AWL

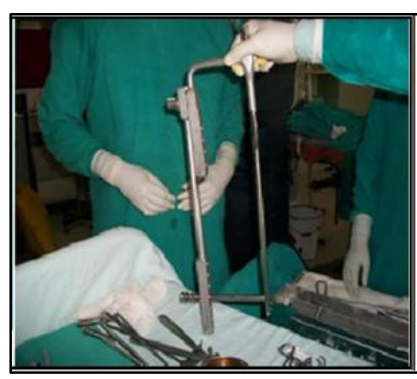

MATCHING DISTAL HOLES OF NAIL \& JIG 


\section{ORIGINAL ARTICLE}

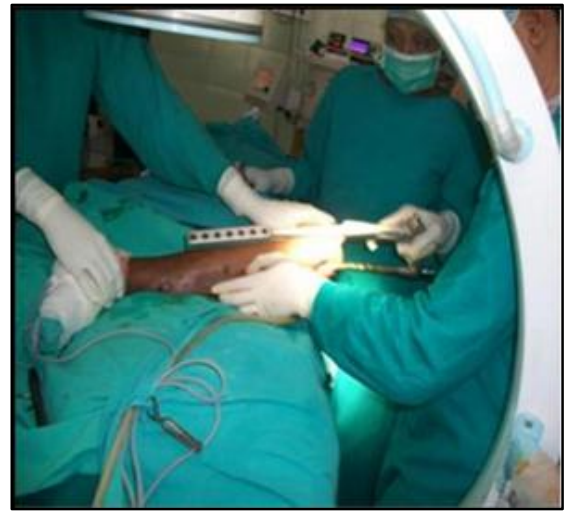

ENTRY OF NAIL ASSEMBLY

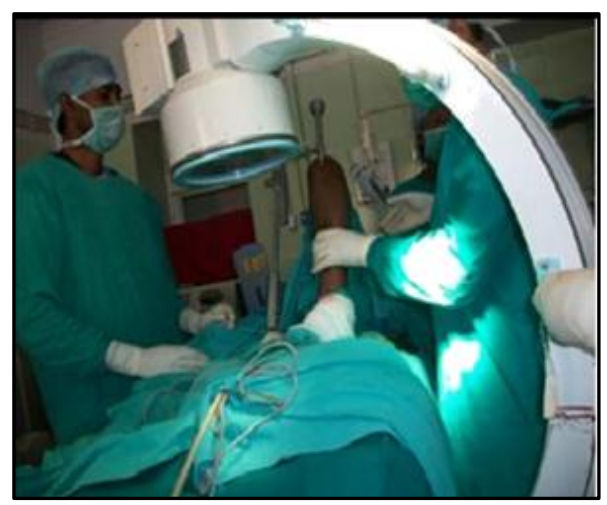

CONFIRMING DISTAL PART OF NAIL

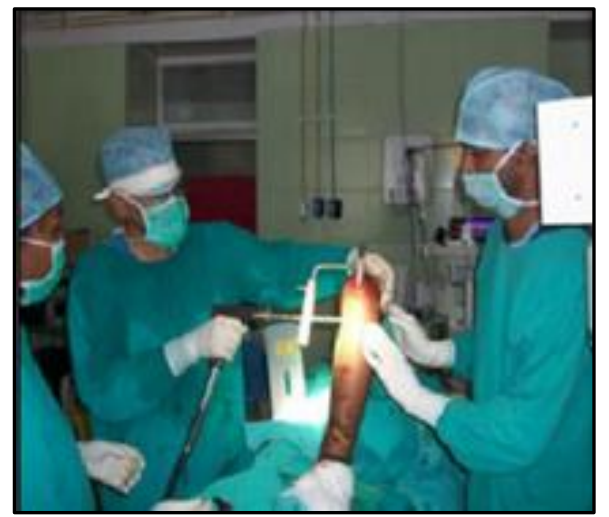

PROXIMAL LOCKING WITH HELP OF JIG

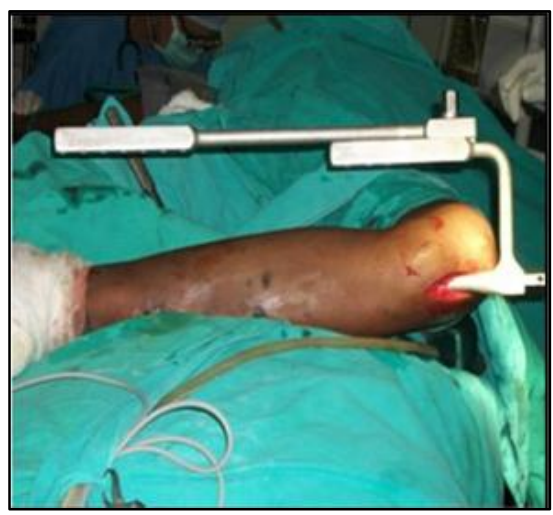

PUSHING NAIL INTO DISTAL FRAGMENT

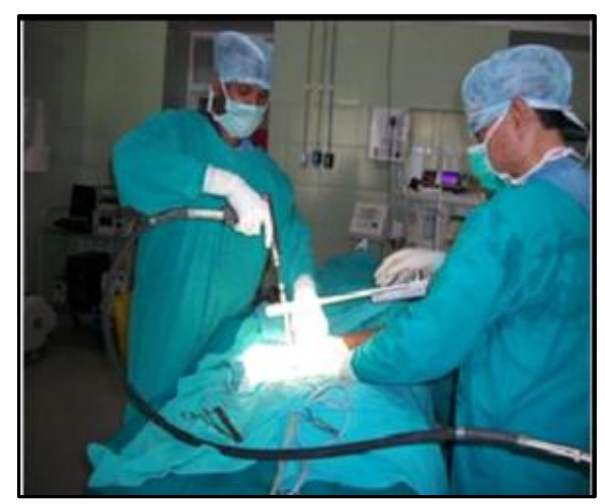

DISTAL LOCKING WITH HELP OF IIG

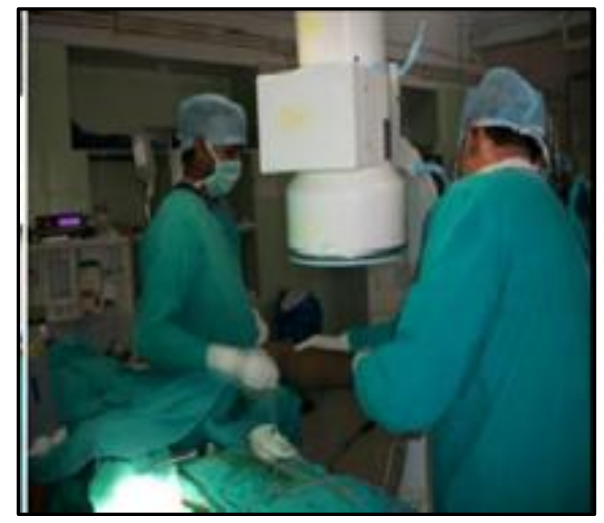

CONFIRMING UNDER C-ARM 


\section{ORIGINAL ARTICLE}

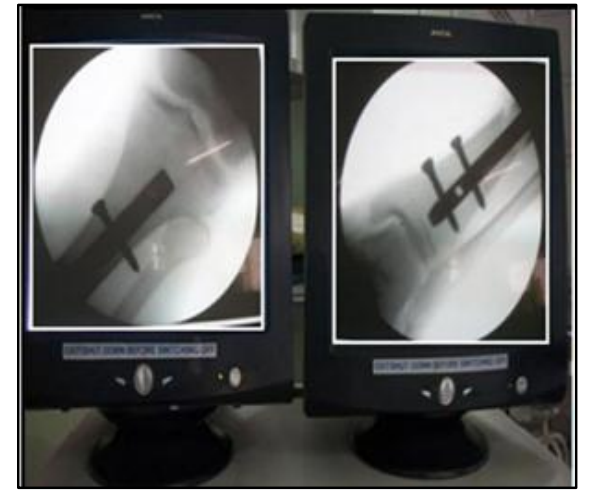

C-ARM IMAGES AT END OF PROCEDURE

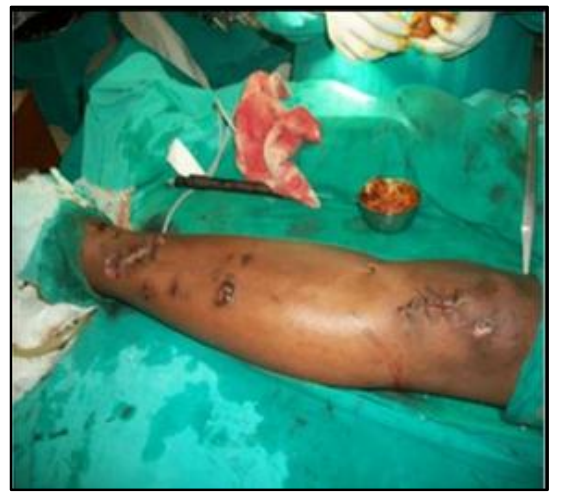

AFTER SUTURING THE INCISIONS

\section{RESULTS WERE ANALYSED IN TERMS OF:}

\begin{tabular}{|c|c|c|c|c|c|c|}
\hline 1. & \multicolumn{3}{|c|}{ Weight bearing: } & & & \\
\hline & \multicolumn{3}{|c|}{ a. Non weight bearing } & : & & \\
\hline & \multicolumn{3}{|c|}{ b. Partial weight bearing } & $:$ & & \\
\hline & \multicolumn{3}{|c|}{ c. Full weight bearing } & : & & \\
\hline \multirow[t]{8}{*}{2.} & \multicolumn{3}{|c|}{$\begin{array}{l}\text { Follow up: } \\
\end{array}$} & & & \\
\hline & & & $8^{\text {th }} \mathbf{w k}$ & $12^{\text {th }}$ wk & $2^{\text {th }}$ wk & 6m \& above \\
\hline & Pain & & & & & \\
\hline & Deformity & & & & & \\
\hline & Range & Knee & & & & \\
\hline & of motion & Ankle & & & & \\
\hline & Shortening & & & & & \\
\hline & Radiological union & & & & & \\
\hline 3. & Time taken & & & & & \\
\hline & a. Wound healing & & & : & & \\
\hline & b. Union & & & : & & \\
\hline
\end{tabular}

Details analysis of results on the basis of following Criteria:

I. Jhoner and Wruh's criteria for evaluation of final results ${ }^{13}$ :

\begin{tabular}{|c|c|c|c|c|c|}
\hline $\begin{array}{r}\text { Sl. } \\
\text { No }\end{array}$ & Criteria & Excellent & Good & Fair & Poor \\
\hline 1 & Non- unions, Osteitis, amputations & None & None & None & Yes \\
\hline 2 & Neurovascular Disturbances & None & Minimal & Moderate & sever \\
\hline 3 & Deformity & & & & \\
\hline & Varus/valgus & None & $2^{0}-5^{0}$ & $6^{0}-10^{0}$ & $>10^{0}$ \\
\hline & Anteroversion & $2^{0}-5^{0}$ & $6^{0}-10^{0}$ & $11^{0}-20^{0}$ & $>20^{0}$ \\
\hline & Recurvation & $2^{0}-5^{0}$ & $6^{0}-10^{0}$ & $11^{0}-20^{0}$ & $>20^{0}$ \\
\hline
\end{tabular}


ORIGINAL ARTICLE

\begin{tabular}{|c|c|c|c|c|c|}
\hline & Rotation & $2^{0}-5^{0}$ & $6^{0}-10^{0}$ & $11^{0}-20^{0}$ & $>20^{0}$ \\
\hline 4 & Shortening & $0-5 \mathrm{~mm}$ & $6-10 \mathrm{~mm}$ & $11-20 \mathrm{~mm}$ & $>20 \mathrm{~mm}$ \\
\hline 5 & Mobility & & & & \\
\hline & Knee & Normal & $>80 \%$ & $>75 \%$ & $<75 \%$ \\
\hline & Ankle & $>75 \%$ & $>50 \%$ & $<50 \%$ & -- \\
\hline & Subtalar & None & Occasonal & Moderate & severe \\
\hline 6 & Pin & Normal & Normal & Insig.Limp & Sig.limp \\
\hline 7 & Gait & Possible & limited & Sev. limited & Impossible \\
\hline 8 & Strenuous activities & & & \\
\hline
\end{tabular}

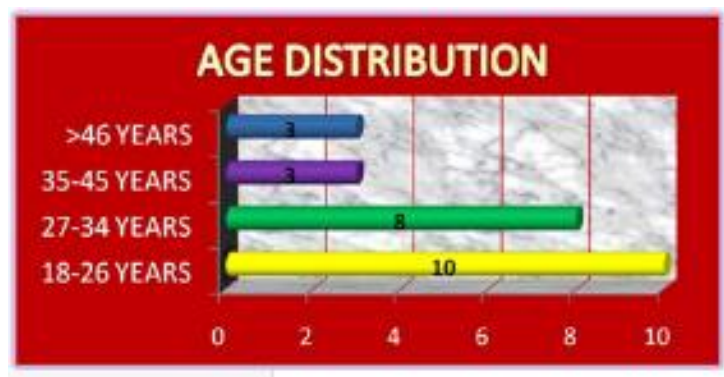

SEX DISTIBUTION

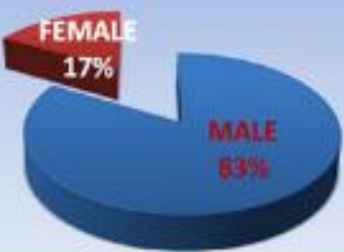

RESULTS: The present study includes 24 open fractures of the tibial shaft surgically treated with interlocking intramedullary nailing without reaming from July 2012 to May 2014 in the department of orthopaedics, Narayana general hospital attached to Narayana medical college, Nellore. The patients have been followed up for at least 6-10 months. All these patients were available for follow up.

1. AGE DISTRIBUTION: Majority of the patients were from age group 21-40 years with average of 32 years, the youngest patient was 18 years old and the oldest patient was of 66 years.

2. SEX DISTRIBUTION: Majority of the patients were twenty males at about $83.33 \%$ and only four (16.67\%) were females.

3. MODE OF INJURY: The commonest cause was high energy trauma accounting for 22 cases and 2 cases were caused by fall from height. Amongst high energy trauma the major cause of fracture was pedestrian automobile accidents which were twelve (50\%) followed by motor cycle accidents which were seven (29.16\%).

4. SIDE OF FRACTURE: Right tibial fracture constituted majority of the patients. Fourteen patients (58.33\%) were having right tibial fractures.

5. FRACTURE CLASSIFICATION: In my study majority of the open fractures of the tibia were Gustilo type II (50\%) and type I (41.66\%). Majority of the fractures occurred at middle distal third of tibia (45.83\%). The predominant tibial fracture pattern was communited (41.66).

6. STATISTICS OF SURGERY: Most of the patients in our study were operated 2-5 days after trauma $(62.5 \%)$, three cases were operated less than 48 hours of trauma (12.5\%), twenty two cases were operated under spinal anaesthesia and two cases under general anaesthesia. In the entire cases midline patellar tendon splitting approach was used for nail insertion.

In nineteen cases $(79.16 \%)$ fracture was fixed with lesser diameter hollow tubular nails without reaming and in remaining five cases soild unreamed tibial nail (AO) was used. In 62.50\% of the cases $8 \mathrm{~mm}$ diameter nails was used. Our mean operation time was 90 minutes. (Range 60 min. to $120 \mathrm{~min}$ ). 


\section{ORIGINAL ARTICLE}

7. COMMENCEMENT OF PARTIAL WEIGHT BEARING: In our study all cases were mobilized with non-weight bearing crunch walking/walker on second to fifth postoperative day. For most of the patients partial weight bearing was started on 11 -21 days postoperatively $(54.17 \%)$. In two cases partial weight bearing was delayed for more than one month $(8.33 \%)$.

8. COMMENCEMENT OF FULL WEIGHT BEARING: Thirteen patients were commenced to protective full weight bearing by 8 weeks postoperatively (54.17\%), in our study most of the patients were commenced to protective FWB by 12 weeks postoperatively $(87.50 \%)$.

9. SECONDARY PROCEDURE: Dynamisation of the nails were done in three $(12.50 \%)$ patients usually between 8-12 weeks. Skin grafting was done in three cases (12.50\%). In one case fasciocutaneous flap was done.

The end results of all twenty four cases are summarized here. All the cases had a follow up between 6-10 months:

I. UNION: union was defined as the presence of bridging callus on two radiographic views and the ability of the patient to bear full weight on the injured extremity. Twenty three of the twenty four fractures united $(95.83 \%)$ by 9 months. The time for union ranged from 3-9 months with an average of 26 weeks, nineteen $(79.17 \%$ ) fractures healed before 26 weeks, four fractures healed between 27-36 weeks, one fracture united within 1 year after the injury.

II. RANGE OF MOTION: One of the essential aspects of closed reduction and internal fixation with interlocking intramedullary nailing without reaming is the ability to mobilise the patient early. In sixteen patients (66.67\%) full range of knee motion was achieved at 12 weeks. Less than $20 \%$ of restriction of flexion was observed in five cases (20.83\%). 20-25\% of restriction of flexion was observed in two cases (8.33\%). In one case (4.16) less than $75 \%$ of knee motion was achieved.
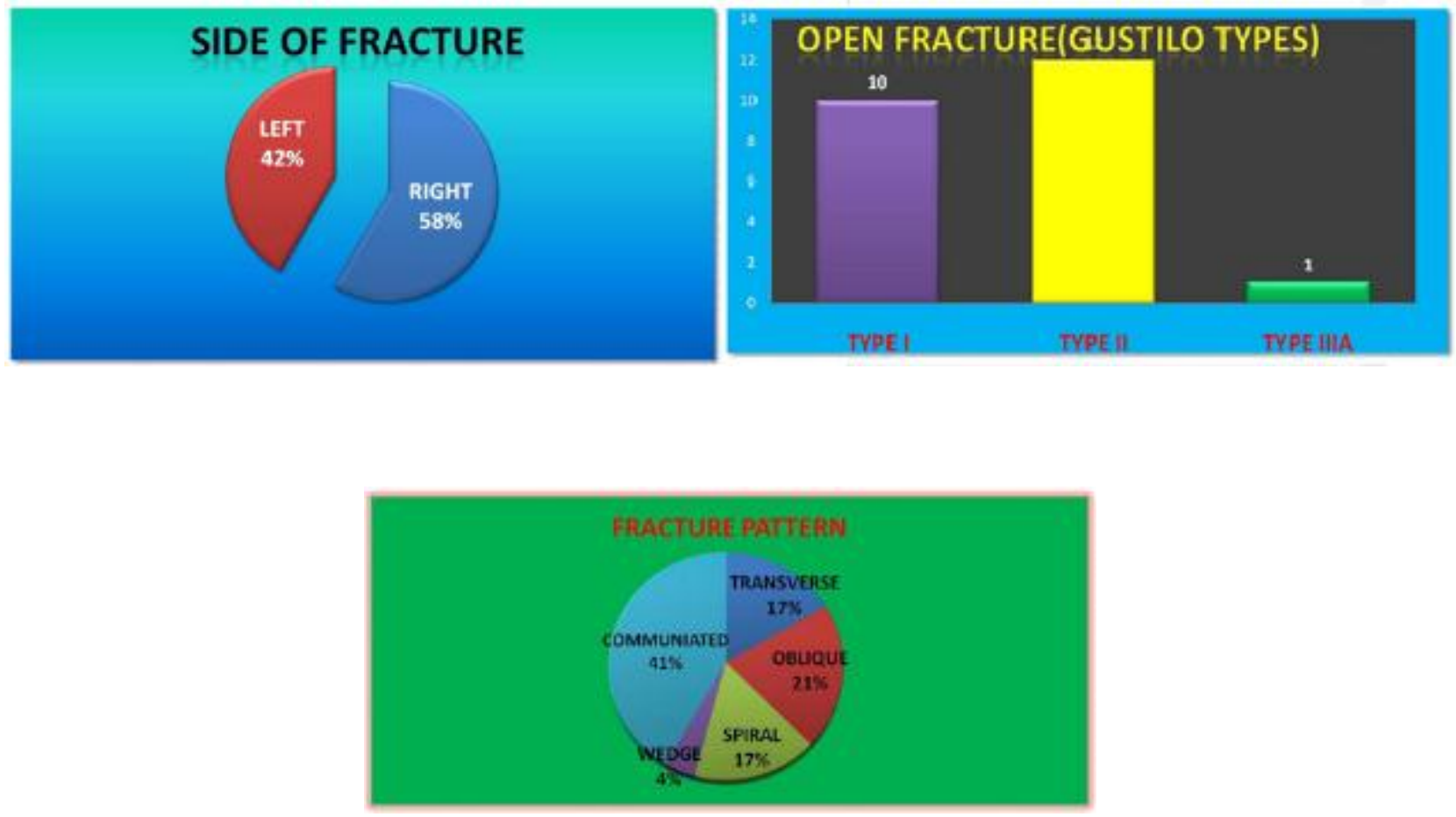

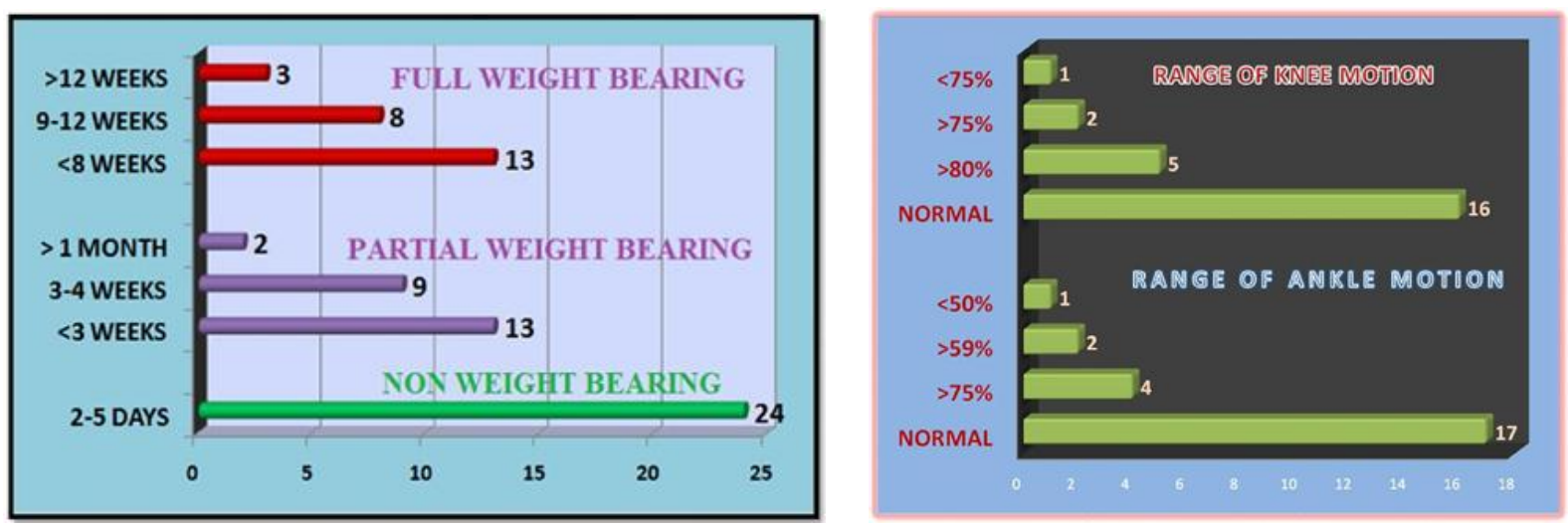

In seventeen patients full range of ankle motion was achieved (70.83\%). More than $75 \%$ of ankle motion was achieved in four patients (16.67\%); in one case less than $50 \%$ of ankle motion was seen $(4.16 \%)$.

III. MALUNION: A malunion was defined as angulation in coronal plane (varus / valgus) of more than $5 \%$ in saggital plane (anterior / posterior) and angulation of $>10^{\circ}$, or more than $10 \mathrm{~mm}$ of shortening. Malrotation was evaluated by comparing the amounts of internal and external rotation of the extremity with those of the injured extremity.

One valgus angulation was noted with less than $7.5^{\circ}$. In one patient anterior angulation less than $7.5^{\circ}$ was noted. Shortening less than $1 \mathrm{~cm}$ was seen in two patients

IV. INFECTION: Two patients developed superficial infections, one in Gustilo type II and one in type IIIA. The two infections were healed with oral antibiotics. One patient developed deep infection in Gustilo type II fracture. He was treated for 6 weeks with I.V. antibiotics.

V. FAILURE OF IMPLANT: Locking screws were broken in two (8.33\%) of the twenty four tibiae, but the breakage did not result in a loss of reduction. None of the nails were broken or were bent. In one case drill bit was broken while attempting locking.

VI. KNEE PAIN: In our study 2 patients (8.33\%) noticed anterior knee pain.

\begin{tabular}{|c|c|c|c|c|}
\hline Sl. No. & & Results & $\begin{array}{c}\text { No. of } \\
\text { Patients }\end{array}$ & $\%$ \\
\hline \multirow{4}{*}{1} & \multirow{4}{*}{ Age } & 18-26 years & 10 & 41.67 \\
\hline & & 27-34 years & 8 & 33.33 \\
\hline & & $35-45$ years & 3 & 12.50 \\
\hline & & $>45$ years & 3 & 12.50 \\
\hline \multirow{2}{*}{2} & \multirow{2}{*}{ sex } & Male & 20 & 83.33 \\
\hline & & Female & 4 & 16.67 \\
\hline \multirow{4}{*}{3} & \multirow{4}{*}{$\begin{array}{c}\text { Mechanism of } \\
\text { injury }\end{array}$} & Pedestrian- MVA & 12 & 50.00 \\
\hline & & M C A & 7 & 29.17 \\
\hline & & M V A & 3 & 12.50 \\
\hline & & Fall & 2 & 8.33 \\
\hline \multirow{2}{*}{4} & \multirow{2}{*}{ Side } & RIGHT & 14 & 58.33 \\
\hline & & LEFT & 10 & 41.67 \\
\hline
\end{tabular}




\section{ORIGINAL ARTICLE}

\begin{tabular}{|c|c|c|c|c|c|}
\hline & & I & & 10 & 41.67 \\
\hline \multirow{2}{*}{5} & \multirow{2}{*}{$\begin{array}{l}\text { Open fracture } \\
\text { (gustilo type) }\end{array}$} & II & & 12 & 50.00 \\
\hline & & III A & & 1 & 8.33 \\
\hline \multirow{5}{*}{6} & \multirow{5}{*}{$\begin{array}{c}\text { Fracture } \\
\text { pattern }\end{array}$} & Transverse & & 4 & 16.67 \\
\hline & & Wedge & & 5 & 20.83 \\
\hline & & Oblique & & 4 & 16.67 \\
\hline & & Spiral & & 1 & 4.16 \\
\hline & & Communited & & 10 & 41.67 \\
\hline \multirow{4}{*}{7} & \multirow{4}{*}{ Fracture level } & Proximal middle & & 1 & 4.16 \\
\hline & & Middle & & 8 & 33.33 \\
\hline & & Middle distal & & 11 & 45.83 \\
\hline & & Distal & & 4 & 16.67 \\
\hline \multirow{3}{*}{8} & \multirow{3}{*}{$\begin{array}{l}\text { Time taken to } \\
\text { surgery from } \\
\text { admission }\end{array}$} & $<2$ Days & & 3 & 12.50 \\
\hline & & 2-5 Days & & 15 & 62.50 \\
\hline & & $>5$ Days & & 6 & 25.00 \\
\hline \multirow{3}{*}{9} & \multirow{3}{*}{ Union } & $<26$ weeks & & 19 & 79.17 \\
\hline & & 26-36 weeks & & 4 & 16.67 \\
\hline & & >36 weeks & & 1 & 4.16 \\
\hline \multirow{7}{*}{10} & \multirow{7}{*}{$\begin{array}{c}\text { Range on } \\
\text { motion }\end{array}$} & \multirow{4}{*}{ Knee } & Full range & 16 & 66.67 \\
\hline & & & $\begin{array}{c}10 \% \text { restriction } \\
\text { of flexion }\end{array}$ & 5 & 20.83 \\
\hline & & & $\begin{array}{c}10-25 \% \text { of } \\
\text { restriction } \\
\end{array}$ & 2 & 8.33 \\
\hline & & & $\begin{array}{c}>25 \% \\
\text { Restriction }\end{array}$ & 1 & 4.16 \\
\hline & & \multirow{3}{*}{ Ankle } & Full range & 19 & 79.17 \\
\hline & & & $\begin{array}{c}>25 \% \\
\text { Restriction } \\
\end{array}$ & 4 & 16.67 \\
\hline & & & $>50 \%$ Restriction & 1 & 4.16 \\
\hline \multirow{6}{*}{11} & \multirow{6}{*}{ Malunion } & \multirow{4}{*}{ Varus/valgus } & $2^{0}-5^{0}$ & - & - \\
\hline & & & $6^{0}-10^{0}$ & 1 & 4.16 \\
\hline & & & $>10^{0}$ & - & - \\
\hline & & & $2^{0-5^{0}}$ & - & - \\
\hline & & \multirow{2}{*}{ anteroversion } & $6^{0}-10^{0}$ & 1 & 4.16 \\
\hline & & & $>10^{0}$ & - & - \\
\hline \multirow{3}{*}{12} & \multirow{3}{*}{ Shortening } & & $0-10 \mathrm{~mm}$ & 2 & 8.33 \\
\hline & & & $10-20 \mathrm{~mm}$ & - & - \\
\hline & & & $>20 \mathrm{~mm}$ & - & - \\
\hline 13 & Nonunion & & & - & - \\
\hline 14 & Implant failure & & & - & - \\
\hline 15 & $\begin{array}{l}\text { Anterior knee } \\
\text { pain }\end{array}$ & & & 2 & 8.33 \\
\hline
\end{tabular}



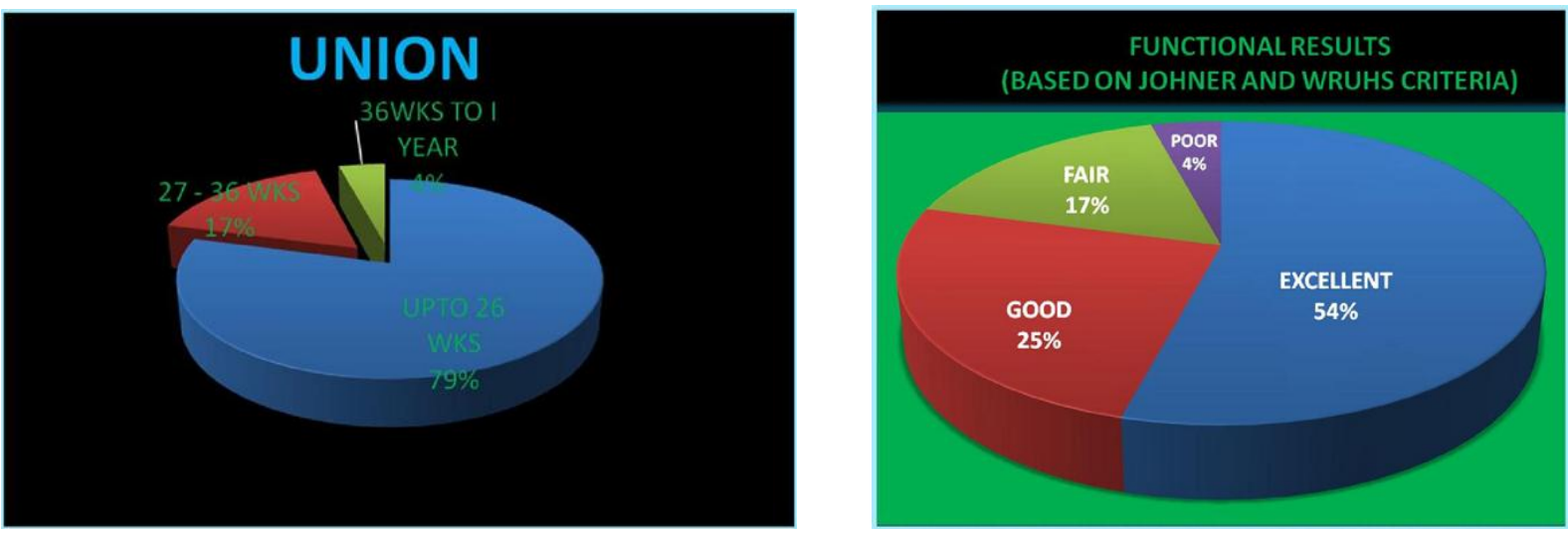

DISCUSSION: Fractures of the tibial diaphysis constitute a spectrum of injuries that result in a loss of the normal unrestricted load-bearing capacity of the leg. This spectrum includes fatigue - type injuries, stable minimally displaced fractures from low-energy trauma, as well as extreme energy-absorbing injuries that result in the loss of soft-tissue envelope continuity, neurologic dysfunction, vascular insufficiency, and loss of bone.

Five distinct philosophies of treatment have evolved, with ardent supporters of each. ${ }^{4}$ Closed reduction with cast or brace immobilization, external fixation, open reduction with internal fixation, and intramedullary nailing techniques are the four major treatment groups; the fifth is the biologic approach to the open tibial fracture, encompassing principle of radical debridement, antibiotic treatment, early wound coverage with plastic surgical techniques, and early bone grafting combined with one of the other four options for bony stabilization (Russel,1996).

Intramedullary nailing without reaming is less damaging to the endosteal blood supply. This is especially important in the treatment of open fractures in which the outer cortical blood supply may be damaged by periosteal stripping. Therefore, closed unreamed interlocking intramedullary nailing combines the most desirable features of external fixation and of non-locking nailing without reaming. Length, alignment and rotation are controlled, the soft tissues are easily accessible and some endosteal blood supply is preserved. These factors should lower the rates of infection and malunions and expand the use of intramedullary nails to fractures near the metaphysic and to those with more severe communition and soft tissue injury.

In the current series 24 cases of open fractures of shaft of the tibial were treated by closed unreamed interlocking intramedullary nailing over a period of two years. They were followed up for an average of 6-10 months. The purpose of this study was to evaluate the end results of treatment in these patients.

These cases were of different age groups, occurred in both sexes and the fracture were of different types and at different levels.

AGE DISTRIBUTION: Most of the patients in my series were in age group of $21-40$ years, which is most active period of life. The average age was 32 years.

The incidence is consistent with other study conducted by Whittle, Russel, and Taylor in the series of fifty patients which showed the average was 34 years. ${ }^{14}$

The average age was 30 years as in the study conducted by Joshi et al on sixty cases of open 


\section{ORIGINAL ARTICLE}

fractures of tibia. ${ }^{15}$ In another study of seventy two open fractures of tibia conducted by the Bonatus et al the average was 30.3 years. ${ }^{14}$

Incidence is consistent with other series previously reported by Donald et al, Henry et al, and Lottes et al. $16,17,18$

Sex Distribution: There were twenty male and four female patients showing male preponderance, which may be due to more outdoor activity of males

The sex distribution in the study conducted by Whittle, Russel, and Taylor were thirty four men and thirteen women and in the study by Mertens et al were thirty four men and seventeen women and Joshi et al fifty two men and four women. ${ }^{19,15,20}$

The Bonatus et al showed that there were fifty two men and nineteen women. ${ }^{14}$ In a study by the Singer et al there were thirty males and eleven females. ${ }^{14}$

Nature of Violence: Majority of the cases sustained fractures from road traffic accidents (91.66) and two patients sustained fracture after a fall as also reported by sarmiento. ${ }^{21}$

Among road traffic accidents, pedestrian - automobile accidents 12 cases (50\%) was most common mode of injury in present series.

In the series reported by Whittle, Russell, and Taylor most of the fractures were caused by high energy trauma and twenty three out of fifty (46\%) were caused by pedestrian - automobile accidents. ${ }^{19}$ In other series reported by singer et al $54.16 \%$ fractures were due to motor vehicle accidents. ${ }^{22}$

RESULTS: In several reported series as well as in our series, the open fractures of shaft of tibia treated with unreamed interlocking intramedullary nailing have given excellent results. In the current series nineteen fractures (79.17\%) united by 26 weeks of injury and other four cases $(16.67 \%)$ united by 36 weeks, which is comparable with the other series as well. The delay in union was noticed in 1 patient with severe communition and extensive soft tissue injury.

In the series reported by Whittle, Russell, and Taylor the average time to union was seven months and four had delayed union. In the series conducted by Joshi et al fourty four of fifty six fractures healed within 32 weeks and six had delayed union. ${ }^{15}$

In the current series, there was one deep infection (4.16\%) in type II open fracture. In the series reported by Whittle, Russell, and Taylor there was incidence of four deep infections among fifty patients (8\%) and in the series by Joshi et al the incidence was $10 \% .{ }^{19}$ Tornetta et al found incidence of $7 \%$ in nail group. ${ }^{23}$ The incidence of deep infection (4.16\%) compares favourably with other series reporting rate of $2.4 \%$ to $11.6 \%$. The infection rate using unreamed locked nails is favourable compared with external fixation (6-14\% deep infection rates) and other methods.

In the current series, two cases of malunions occurred (8.33\%). In the series reported by Whittle, Russell, and Taylor there was there was no malunions. ${ }^{19}$

Santoro et al found a non - union rate of $3 \%$ in 33 patients, a malunion rate of $9 \%$ an infection rate of $3 \%$, nail breakage in 65 and two screws that broke. 24

In the current series the implants failed infrequently, and locking screws were broken in one tibiae (4.16\%), but the breakage did not result in a loss of reduction on the basis of this study, we now recommend dynamisation of most statically locked nails at 8-12 weeks if callus is not evident to promote fracture union and to avoid fracture of the inter locking screws. Our results were comparable with other series of studies. 
In the current series, sixteen patients had (66.67\%) full of knee motion, in seventeen patients (70.83\%) full range of ankle motion at 12 weeks of injury. In the study conducted by Whittle, Russell, and Taylor the flexion at knee was averaged $139^{\circ}$ and motion at ankle averaged $16^{\circ}$ of dorsiflexion and $38^{0}$ degrees of planter flexion. ${ }^{19}$ These results are comparable with other series of studies.

In the current series two patients (8.33\%) noticed anterior knee pain. We advocated techniques of using a more lateral entry point and hyperflexing the knee during nail insertion to reduce the incidence of anterior knee pain. In the series reported by Joshi et al $17.85 \%$ patients had anterior knee pain and series reported by Court Brown et al reported 36\% incidence of anterior knee pain. ${ }^{15,25}$

In the current series, no patient developed fat embolism, compartment syndrome, peroneal nerve palsy and reflex sympathetic dystrophy.

Results were analysed based on following criteria.

Based on Johner and Wruh,s criteria thirteen (54.17\%) patients had excellent results, six (25\%) patients had good results, four (16.67\%) patients had fair results and one (4.16) patient had poor result.

SUMMARY: Twenty four patients who had 24 open fractures of the tibial shaft were treated with wound debridement and interlocking intramedullary nailing without reaming during the period from July 2012 to May 2014, at Narayana Medical College, Nellore. All the cases were fresh fractures and traumatic in nature.

Twenty four patients with fractures of the tibial shaft were available for the study. They were followed for a period of 6-10 months

Our aim was to treat these fractures by closed interlocking intramedullary nailing without reaming, early mobilization and to assess the outcome of unreamed interlocking nailing in the treatment of these fractures.

The mean age of patients with these fractures was 32 years and the maximum patients were in the age group of $21-40$ years. Males predominated in our study. Pedestrian - automobile accidents are the main cause of these fractures followed by motor cycle accidents.

In the current series most of them are Gustlio type II which were twelve fractures (50\%), type I were ten fractures and type IIIA were two fractures. Ten $(41.67 \%)$ fractures were communited followed by four fractures were transverse, four fractures were oblique, five fractures were wedge, and one fracture was spiral and no segmental fractures. Most of the fractures $45.83 \%$ occurred at the junction of middle - distal third of tibia.

All the patients were examined clinically and radiographically, including detail history of premorbid status and occupation at the time of admission. Patients fulfilling the inclusion criteria was only included in the study.

Emergency irrigation and debridement of the open fracture was done. Patients were operated as early as possible once the general condition of the patients was stable and fit for surgery. Most of the cases surgery was performed in $2-5$ days (62.50\%) of trauma.

In all cases midline patellar tendon splitting approach was used for nail insertion site. In one case drill bit was broken, while drilling the proximal holes. Our mean operating time was 90 minutes (Range $60 \mathrm{~min}$ to $120 \mathrm{~min}$ ).

All the patients were mobilized post operatively as early as possible depending upon the fracture stability, general condition, and tolerance of the patient.

Nineteen fractures united within 26 weeks of injury and four cases united by 36 weeks, one 
case of delayed union, which united within one year. In sixteen patients (66.67\%) here was full range of knee motion at 12 weeks. More than $80 \%$ of knee motion was seen in five cases and in two cases more than $75 \%$ of knee motion was seen. In one cases less than $75 \%$ of knee motion was achieved. In seventeen patients $(70.83 \%)$ full range of ankle motion at 12 weeks, more than $75 \%$ of ankle motion in four cases $(16.67 \%)$ and more than $50 \%$ of ankle motion in two cases $(8.33 \%)$. There was less than $50 \%$ of ankle motion in one cases (4.16\%).

In one cases valgus angulation was noticed less than $7.5^{0}$ and in one patient anterior angulation of 7.5 $5^{0}$. Shortening noticed in two patients of less than $1 \mathrm{~cm}$.

Two patients developed superficial infection. All were healed with antibiotics. One patient developed deep infection in Gustilo type II open fracture. Locking screws broke in one case, at the distal locking holes, but the breakage did not result in a loss of reduction and union occurred within 32 weeks of trauma. Two patients were noticed with pain at the knee joint.

Closed intramedullary interlocking nailing without reaming is feasible in open fractures of shaft of tibia up to Gustilo type IIIB. Image intensifier has revolutionized the treatment of tibial shaft fractures by making the technique easier.

The present series shows that open fractures of the tibial shaft, managed well with unreamed interlocked intramedullary nailing, involves minimal surgical trauma and negotiable blood loss. It provides the advantages of early ambulation, lower rates of infection, delayed union, non - union and malunions compared to other treatment modalities. To achieve these goals, we recommend early extensive debridement and stabilization with unreamed interlocking intramedullary nail followed by early wound coverage if required. Fracture should be dynamised at $8-10$ weeks, if union does not progress to prevent the unwanted complication of non-union or delayed union.

A significant advantage of interlocking in addition to early joint motion, early weight bearing allows earlier return to work.

In our series we found that unreamed interlocking nailing in open fractures of tibial shaft is feasible and showed excellent and good results in $95.83 \%$ patients with minimal complications.

\section{CONCLUSION:}

1. Closed unreamed interlocking intramedullary nailing with the help of image intensifier seems feasible in open diaphyseal fractures of tibia.

2. Minimal blood loss.

3. Minimal risk of infection.

4. Early mobilization of the patient which helps in healing of the fracture and prevents joint stiffness.

5. Promotes early union as it does not disturb the anatomy and physiology of vascularity at the fracture site.

6. Simpler follow - up, escaping repeated visits, plaster changes, wedging and check radiographs.

7. Earlier soft tissue coverage, fracture dynamisation at $8-12$ weeks if union does not progress to prevent the unwanted complications of non-union or delayed union. We are also of the opinion that ideally locking all the proximal and distal holes to avoid malunions and fatigue of locking bolts.

8. Strict adherence to technical principles during nailing might have prevented some of the complications that developed in this series.

9. Minimal hospital stay and early returns to activities. 
10. Acceptable complications rate as compared to other modalities of treatment.

11. Overall reduced morbidity.

12. Cost effective as per reduced need for outpatient care, earlier return to work and cessation of sick benefit compensation.

\section{REFERENCES:}

1. Court- Brown CM, McBirnie J. The epidemiology of tibial fractures. J Bone Joint Surg 1995; 77B: $417-21$.

2. Ruedi T, Webb JK, Allgwer M. Experience with the dynamic compression plate (DCP) in 418 recent fractures of the tibial shaft. Injury 976; 7: $252-257$.

3. Charnley J 1961 the closed treatment of common fractures, $3^{\text {rd }}$ edition, livingstone, Edinburg, ch. 15, p 105.

4. Charley J, "Fractures of the shaft of tibial." The closed treatment of common fractures, Edinburg, Churchill Livingstone, 1961: p 209 - 249.

5. Nicoll EA, 1964: "Fractures of the tibial shaft; a survey of 705 cases". J Bone Joint Surg, 46B: 373387.

6. Canale \& Beaty: Campbell's operative Orthopaedics, Vol. 3; $11^{\text {th }}$ edition, 2008. Mosby publishers, pages $3117-3146$.

7. Brown PW, Urban JG, 1969: "early weight bearing treatment of open fractures of the tibial: An end result study of 63 cases: JBJS 51 - A59 - 75.

8. Bach AW, and Hansen Jr.ST, 1989: "plates versus external fixation in severe open tibia shaft fractures: A randomized study: Clin Orthop: 241: 89-94.

9. Watson - Jones: "Injuries of the leg" Chapter - 32 in Watson Jones fractures and joint injuries $7^{\text {th }}$ Edn, Wilson (Ed), B.I. Churchill livingstone, New Delhi, 2009, p 949.

10. Smith JE 1974: "Results of early and delayed internal fixation for tibial shaft fractures: A review of 470 fractures. "J Bone joint surgery (Br), 56 -B $469-477$.

11. Holbrook JL, Swiontiowski MF, sanders R 1989: "treatment of open fractures of the tibial shaft: Ender nailing versus external fixation; a randomized prospective comparsion" J B J S 71 - A: 1231 $-1238$.

12. Rhinelander FW, 1974: "Tibial blood supply in relation to fracture healing." Clin Orthop, 105: 3481.

13. Johner R, Wruhs 0: 1982: Classification of tibial shaft fractures \& correlation with results after rigid fixation: Cli. Orth. 178; 7-25.

14. Bonatus T; Olson S.A.; Les S; \& Chapman M W.: Nonreamed locking intramedullary nailing for open fractures of the tibia. Unpublished data.

15. D. Joshi, A. Ahmed, L Krishna, Y Lal., 2004 "Unreamed interlocking nailing in open fracture of tibia" J. ortho. Surg.; 12(2); 216-221.

16. Donald and Davidson Seligson: Treatment of tibial shaft fractures by percutaneous Kuntscher nailing, CORR. Sep.1983; No. 178: 7-24.

17. Henley M B: non- reamed versus external fixators. Presented at Annual Meetings of orthopaedic Trauma Society Los Angeles CA, 1994.

18. Lottes J0., 1974: "Medullary nailing of the tibial with the triflange nail".Clin Orthop, 105: 253.

19. Whittle AP., Russell TA., Taylor JC., Lavelle DG., 1992: "Treatment of open fracture of the tibial shaft with the use of interlocking nailing without reaming". J Bone Joint Surg, 74 A; 1162-1171 


\section{ORIGINAL ARTICLE}

20. P. Mertens, p. Broos, p. Rryders, R Deswart, “The undreamed intramedullary tibial nail: A Follow up study in 51 patients" Acta Ortho. Belgica Vol. 64 - 3 - 1998.

21. Sermiento A. 1967: "Functional below knee cast for tibial fracture". J Bone joint surg (AM), 49: 855.

22. Singer R W, kellam JF: Open tibial diaphyseal fractures. Results of undreamed locked intamedullary nailing, Cli Orth. 1995; 315: 114-118.

23. Tornetta, P., III; Bergman, M.; Watnik, N.; Berkowitz, G.; and Steuer, J.: Treatment of grade- HIB open tibial fractures. A prospective randomized comparison of external fixation and non-reamed locked nailing/Bone and Joint Surg., 76-B (1): 13-19, 1994.

24. Santoro V, Henley M, Benirschke S, et al: Prospective comparison of unreamed interlocking IM nails versus half-pain external fixation in open tibial fractures. Presented at OTA, Toronto, Nov. 10, 1990.

25. Court Brown CM., and Hugher SPF., 1985: "Hughes external fixatior in treatment of tibial fractures". J Soc Med., 78: 830- 837.

\section{AUTHORS:}

1. K. Harsha Kumar

\section{PARTICULARS OF CONTRIBUTORS:}

1. Associate Professor, Department of Orthopaedics, Narayana Medical College,

FINANCIAL OR OTHER

COMPETING INTERESTS: None

\section{NAME ADDRESS EMAIL ID OF THE} CORRESPONDING AUTHOR:

Dr. K. Harsha Kumar, Associate Professor, Department of Orthopaedics, Narayana Medical College,

E-mail: drharshaortho@gmail.com

Date of Submission: 05/05/2015.

Date of Peer Review: 06/05/2015.

Date of Acceptance: 23/05/2015.

Date of Publishing: 03/09/2015. 